
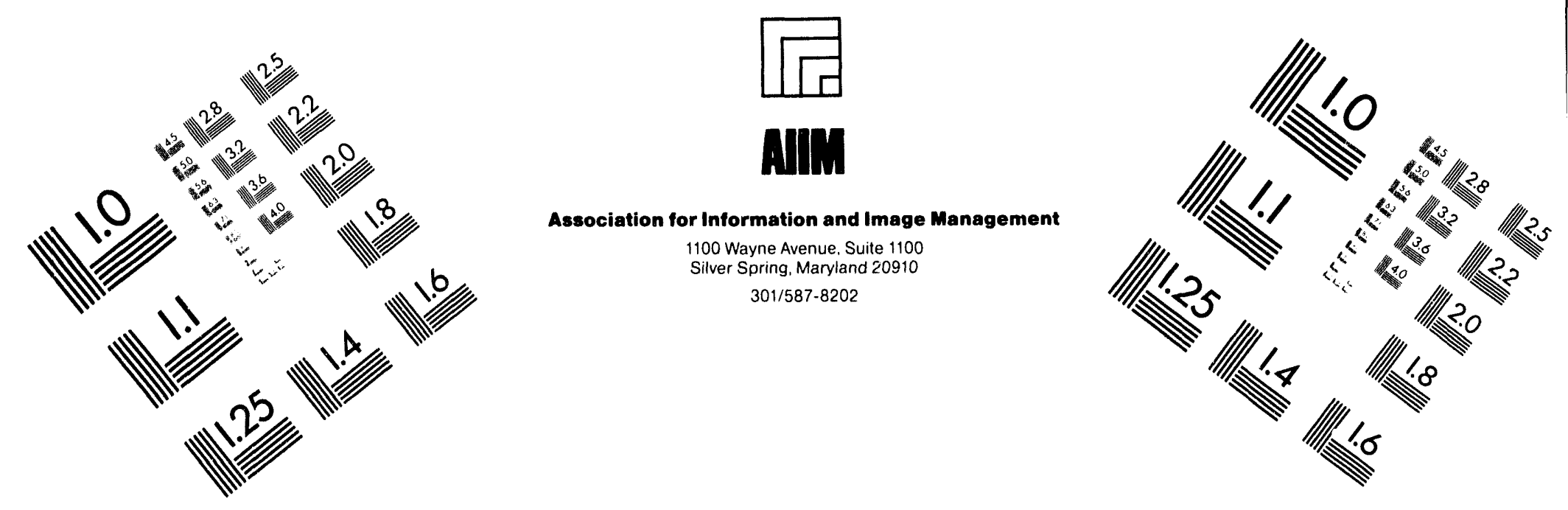

Centimeter

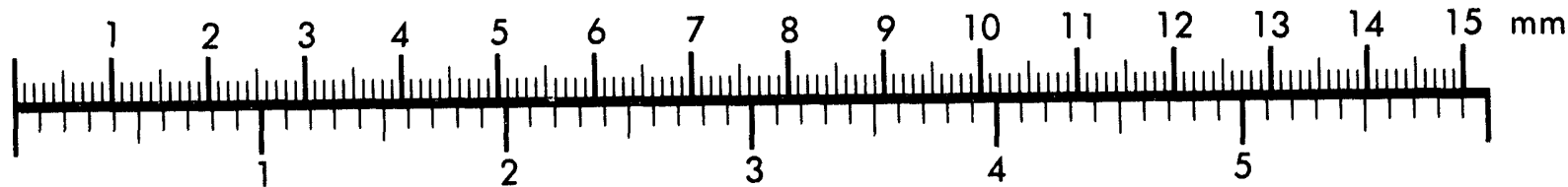
Inches
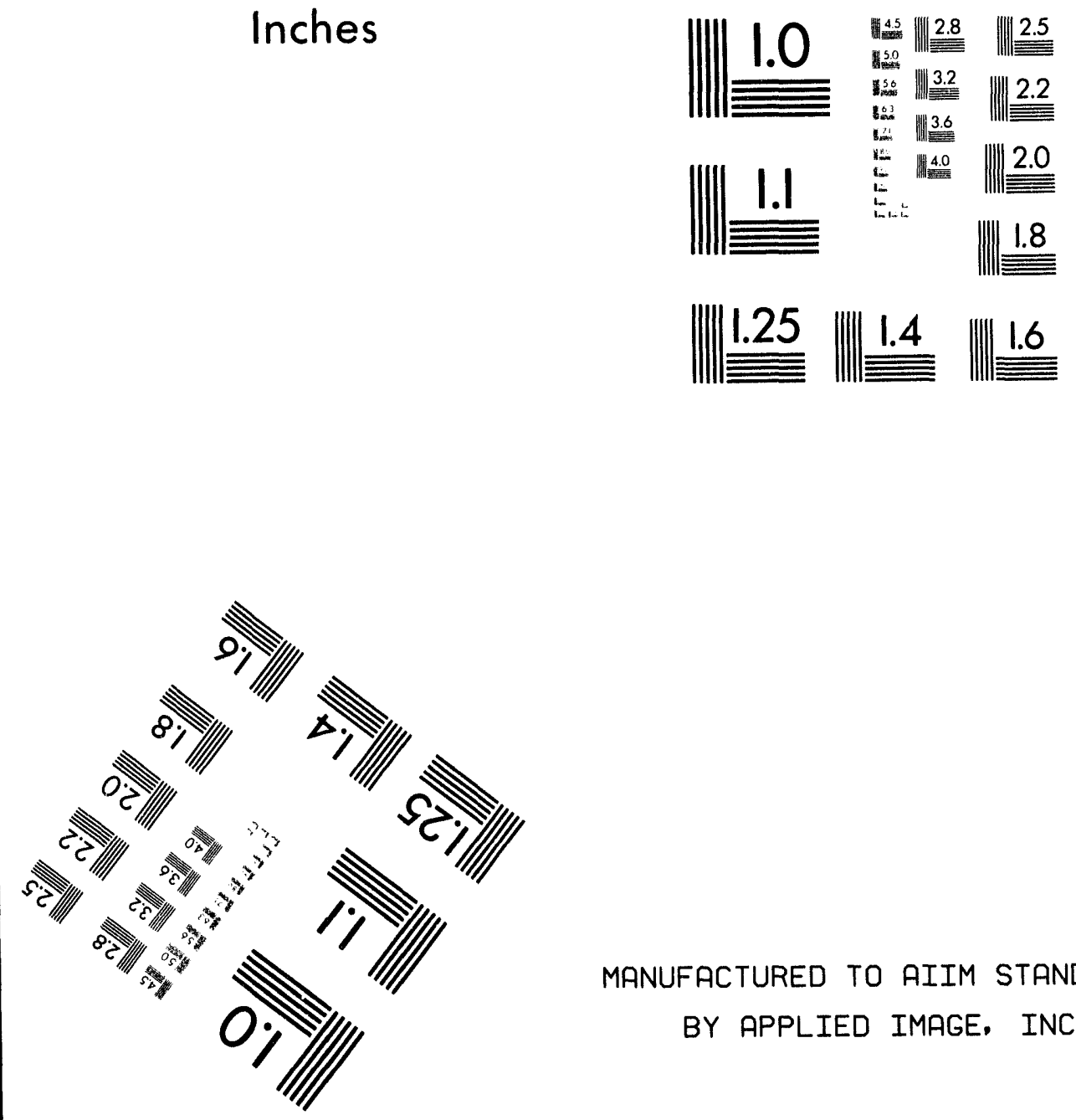

MANUFACTURED TO AIIM STANDARDS

BY APPLIED IMAGE. INC.

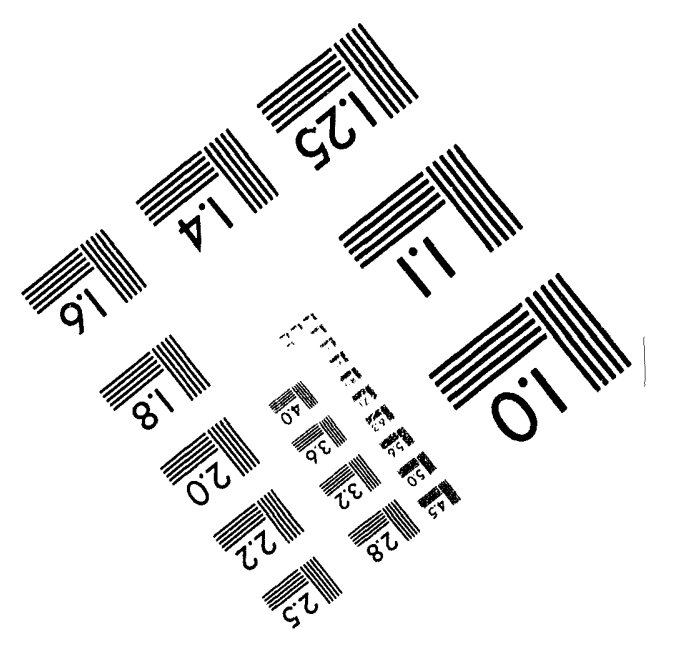



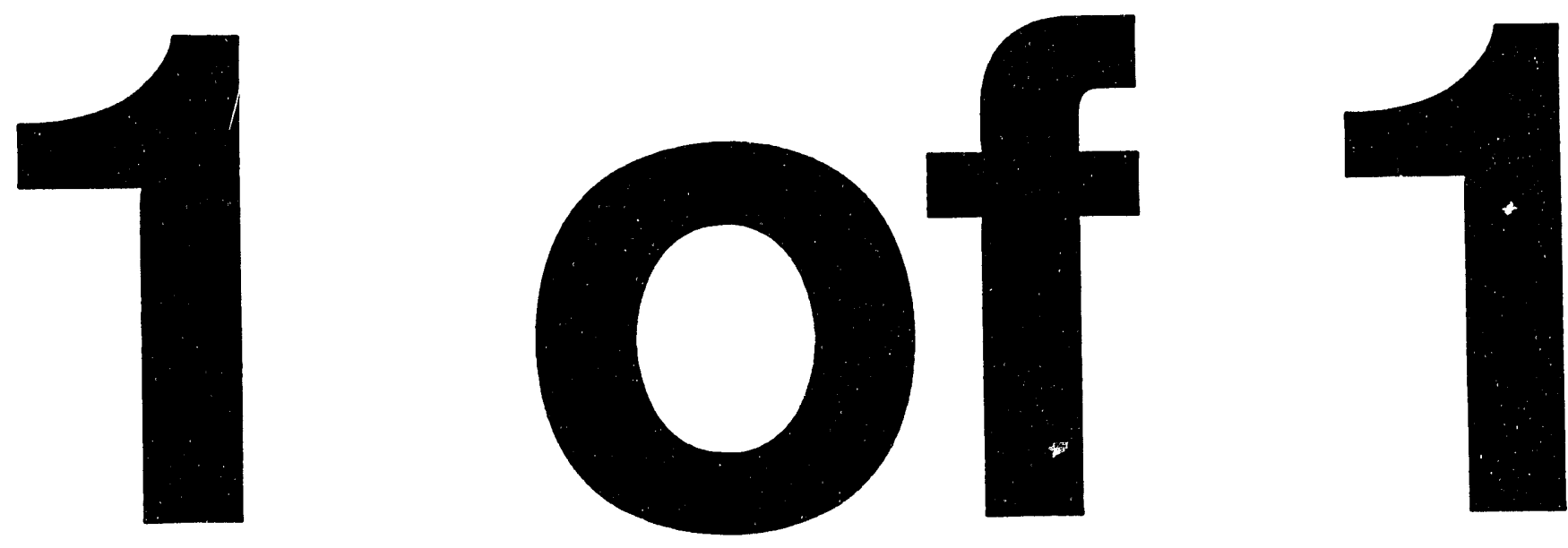
UCRL-JC-115583

PREPRINT

\title{
Target Area Design Basis and System Performance for the National Ignition Facility
}

\author{
M. Tobin, V. Karpenko, K. Hagans \\ A. Anderson, J. Latkowski, R. Warren \\ (Lawrence Livermore National Laboratory) \\ R. Wavrik, R. Garcia, J. Boyes \\ (Sandia National Laboratories)
}

This paper was prepared for submittal to the

American Nuclear Society

11th Topical Meeting on the Technology of Fusion Energy

New Orleans, Louisiana

June 19-23, 1994

June 1994

This is a preprint of a paper intended for publication in a journal or proceedings. Since changes may be made before publication, this preprint is made available with the understanding that it will not be cited or reproduced without the permission of the author. 


\section{DISCLAIMER}

This document was prepared as an account of work sponsored by an agency of the United States Government. Neither the United States Government nor the University of California nor any of their employees, makes any warranty, express or implied, or assumes any legal liability or responsibility for the accuracy, completeness, or usefulness of any information, apparatus, product, or process disclosed, or represents that its use would not infringe privately owned rights. Reference herein to any specific commercial products, process, or service by trade name, trademark, manufacturer, or otherwise, does not necessarily constitute or imply its endorsement, recommendation, or favoring by the United States Government or the University of California. The views and opinions of authors expressed herein do not necessarily state or reflect those of the United States Government there of, and shall not be used for advertising or product endorsement purposes. 


\section{TARGET AREA DESIGN BASIS AND SYSTEM PERFORMANCE FOR THE NATIONAL IGNITION FACILITY}

\author{
M. Tobin, V. Karpenko, K. Hagans, \\ A. Anderson, J. Latkowski, R. Warren \\ University of California \\ Lawrence Livermore National Laboratory \\ P.O. Box 808 \\ Livermore, CA 94550 \\ (510) 423-1168
}

\author{
R. Wavrik, R. Garcia, J. Boyes \\ Sandia National Laboratories \\ P.O. Box 5800, MS-1184 \\ Albuquerque, NM 87185-1184
}

(505) 845-7090

\section{OVERVIEW}

The NIF Target Area is designed for ICF experiments with the goal of fusion ignition. The Target Area must provide appropriate conditions before, during, and after each shot. The repeated introduction of large amounts of laser energy into the chamber and emission of fusion energy from a cryogenic target represent new challenges in ICF facility design. Prior to a shot, the facility provides proper illumination geometry, target chamber vacuum, and a stable platform for the target and its diagnostics. During a shot, the impact of the energy introduced into the chamber is minimized, and workers and the public are protected from excessive prompt radiation doses. After the shot, the residual radioactivation is managed to allow required accessibility. Tritium and other radioactive wastes are controlled and disposed. Diagnostic data is also retrieved, and the facility is readied for the next shot.

The Target Area will accommodate yields up to $20 \mathrm{MJ}$, with a maximum credible yield of $45 \mathrm{MJ}$. The target area's design lifetime is 30 years. The Target Area provides the personnel access needed to support experimentation with its precision diagnostics. The annual shot mix for design purposes is shown in Table 1. Designing to this experimental envelope ensure: the ability and flexibility to move through the experimental campaign to ignition efficiently.

\begin{tabular}{|c|c|}
\hline $\begin{array}{c}\text { Total Target } \\
\text { Output (MJ) } \\
\text { [Fusion Yield] }\end{array}$ & $\begin{array}{c}\text { Number } \\
\text { of shots }\end{array}$ \\
\hline \hline 1.0 & $250-500$ \\
1.5 & $250-500$ \\
1.8 & $50-150$ \\
$1.9[100 \mathrm{~kJ}]$ & 100 \\
$6.8[5 \mathrm{MJ}]$ & 35 \\
$21.8[20 \mathrm{MJ}]$ & 10 \\
\hline
\end{tabular}

Table 1. Assumed annual NIF target experiments for design purposes

The NIF is configured in a "U-shape" with the Target Area at the base of the "U". This arrangement preserves the ability to add a second larget area at some future date. The NIF target chamber is a $10 \mathrm{~cm}$ thick aluminum sphere with a $5 \mathrm{~m}$ radius, as shown in Figure 1. The chamber and target area support structures will become radioactive following shots producing neutrons. Shielding on the chamber exterior is provided to reduce activation of structures as well as reduce the dose from the radioactive decay of the chamber. Controlled or monitored access to the chamber area is required for up to several days after shots producing fusion yields of more than a few MJ. Access is planned so that the maximum annual occupational dose is less than $1 / 10$ of that given in DOE Order 6400.11 which specifies less than 5 rem annual exposure. To provide the required stability and radiation levels at a reasonable cost the target chamber support structure is made from aluminum-reinforced, borated concrete.

For the first year or two, targets will be limited to disks and non-igniting, non-cryogenic hohlraums held in place with the initial NIF target positioner. When cryogenic experiments begin, the fusion target and its cryogenic support system will be held at chamber center by a positioner. A representative cryogenic system, shown in Figure 2, uses two capillary tube loops extending $~ 10$ $20 \mathrm{~cm}$ from the end of the positioner and filled with $\mathrm{He}$ at $200 \mathrm{~atm}$ and $\sim 10 \mathrm{~K}$. The tubes are $200 \mathrm{~mm}$ OD and $125 \mathrm{~mm}$ IDvb. ' To prevert frost build-up from affecting target performance, the chamber vacuum is less than $10^{-5}$ Torr while the cryo target is present. Non-ignition targets, such as dudded targets, disks, or empty hohlraums will be held on a stalk as on Nova. Cryogenic targets will have a small capsule (CH mass $\approx 3 \mathrm{mg}$, D mass of about $0.08 \mathrm{mg}$, and $T$ mass of about $0.125 \mathrm{mg}$ ) inside a gold hohlraum of mass $110 \mathrm{mg}$. The cylindrical hohlraum is / $\mathrm{mm}$ long and $5.5 \mathrm{~mm}$ in diameter with $2.8 \mathrm{~mm}$ diameter laser entrance holes in the end faces. The entrance holes are covered with $1 \mu \mathrm{m}$ thick polyimide windows which maintain a 0.67 atm $\left(0.2 \mathrm{mg}\right.$ at density $-3 \mathrm{mg} / \mathrm{cm}^{2}$ ) helium (at $4 \mathrm{~K}$ ) inside the hohlraum. The mass of the heat sink material (between the capillary tubes and the hohlraum, assumed to be $\mathrm{Cu}$ ) is $\approx 200 \mathrm{mg}$ while that of the rings of steel tubing encircling the hohlraum is $\approx 10 \mathrm{mg}$.

Twelve-inch diameter manipulator tubes are mounted on the chamber at. above and below the equator 


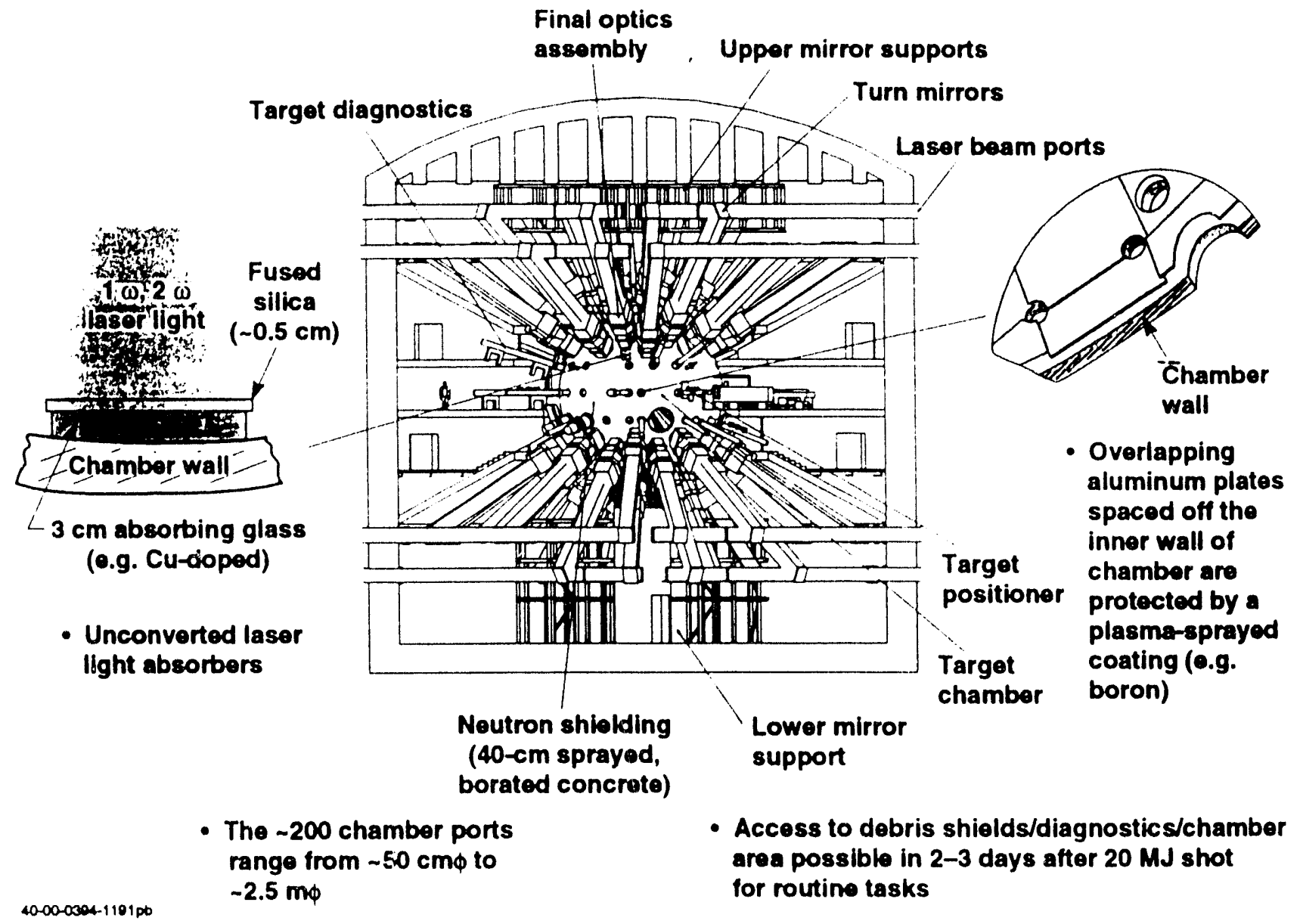

Figure 1. NIF target area. 
to allow insertion of diagnostic systems and experimental apparatus. Diagnostics not designated a specific beam por will be adapted for insertion into these tubes. Experiments not supporting ignition, such as samples exposed to ncutrons, $x$-rays, and/or debris for chamber dynamics studies, can also be introduced through this method. Larger experimental packages will be accommodated by the large ports at the poles of the chamber, and on the equator.

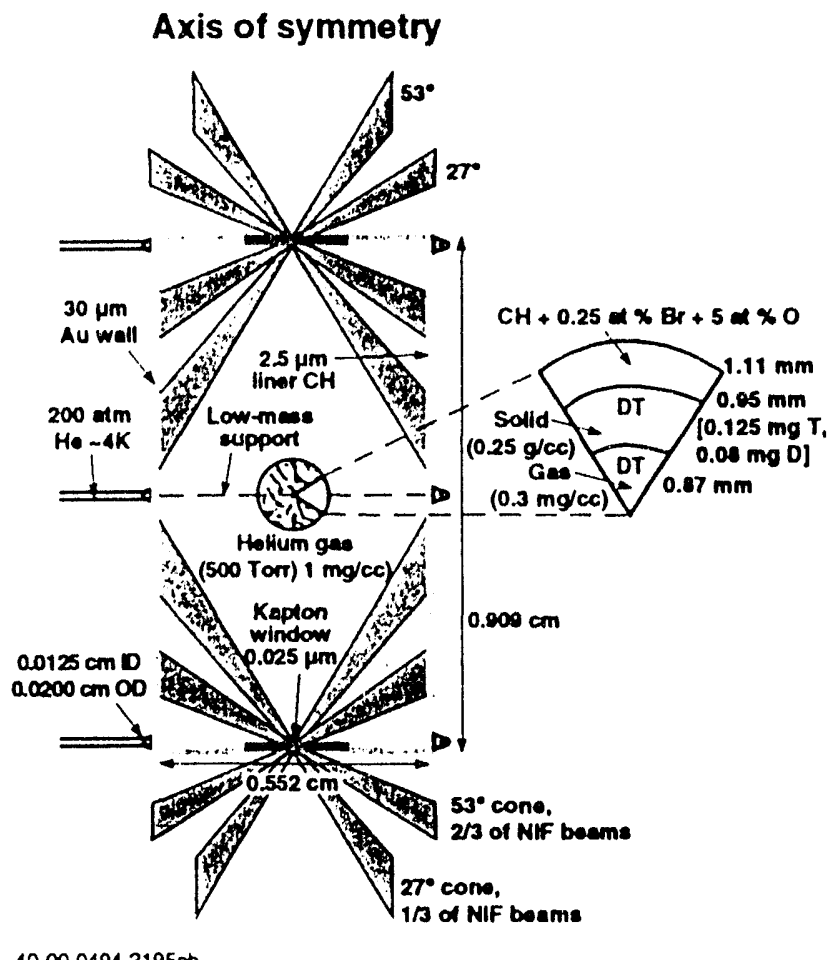

$40-00-0494-218500$

Figure 2. NIF beam number and orientation (>192) meets implosion symmetry requirements for baseline target design.

The tritium throughput for a year will be $\sim 300$ $600 \mathrm{Ci}$ with $2 \mathrm{Ci}$ of tritium in each cryogenic target intended for DT yield. After the admission of a DT target into the chamber for an experiment producing yield, tritium is nearly entirely removed from the chamber through the vacuum system where it is trapped on a molecular sieve. At periodic intervals filters are removed and disposed of in accordance with DOE regulations. The largest tritum inventory at any time in the facility will not exceed $300 \mathrm{Ci}$. The annual routine tritium release will be $\leq 10 \mathrm{Ci}$

Decontamination of surface tritium and activated debris will be accomplished employing carefully adapted $\mathrm{CO}_{2}$ cleaning technology. Robotic systems will perform in-chamber cleaning functions while a near-chamber decontamination facility (glove-box) will support cleaning components, tools, and equipment. Special vacuum systems associated with the $\mathrm{CO}_{2}$ cleaners will recover the target and other debris ( 100 grams/yr) for safe storage and periodic removal.

\section{PRELIMINARY TIME AND MOTION STUDY}

Access to the area near the target chamber may be required, even after a fusion yield shot of a $100 \mathrm{~kJ}$ or more, despite the anticipated large stand-offs for Phase II diagnostics (> 10's of $\mathrm{m}$ ). A time and motion sturly was performed to establish whether necessary tasks can be performed at a rate sufficient to meet the annual shot mix of Table 1. The post-shot decay radiation due to neutron activation is of concern since it will limit post-shot target area entry of NIF target area workers. Shielding is used to reduce the degree of activation and the dose rate from the activation that does occur.

The chamber shielding thickness is chosen so that the average dose rate 24 hours after a $100-\mathrm{kJ}$ shot is $0.64 \mathrm{mrem} / \mathrm{hr}$ in the vicinity of the exterior of the chamber shielding. Routine access into the target chamber itself will be unnecessary.

Access into the target area room after a yield of $100 \mathrm{~kJ}$ or more is routinely necessary to perform several tasks:

- To load and insert a new target into the breech of the target positioner.

- To remove debris shields for maintenance.

- To set up or take down diagnostics.

The average times for these tasks, the average radiation level likely in the location(s) the tasks are performed, and the maximum number of times an individual is likely to perform a task has been evaluated for the shot mix of Table 1 . The results, including estimated annual doses for each task, are summarized in Table 2.

\section{CONFINEMENT}

While preliminary, the results indicate that no worker will receive more than $10 \%$ of the limit $(5000$ mrem/year) set by DOE Order 6400.11 during any year of operation of the NIF. This initial estimate suggests that, conceptually, the experimental plan can be safely accomplished.

Confinement of fusion experiments in an inertial fusion system includes several tasks: withstanding the pressure pulse of the release of energy by the target, maintaining $\geq$ $97 \%$ transmission of debris shiclds due to any surface contamination or bulk material damage, shielding against prompt radiation doses, and reducing neutron radioactivation to acceptable levels. Maintenance of the 
Table 2. Resuits of a preliminary time and motion study in neutron activated areas of the target area for routine postyield shot activities.

\begin{tabular}{|l|l|l|l|l|l|}
\hline Task & $\begin{array}{l}\text { Duration } \\
\text { [hours] }\end{array}$ & $\begin{array}{l}\text { Radiation } \\
\text { Level } \\
\text { [mrem/hr] }\end{array}$ & $\begin{array}{l}\text { Frequency } \\
\text { [times in one } \\
\text { year] }\end{array}$ & $\begin{array}{l}\text { Number of } \\
\text { Exposed } \\
\text { Personnel }\end{array}$ & $\begin{array}{l}\text { Annual Dose } \\
\text { [mrem] }\end{array}$ \\
\hline \hline Targets & 0.5 & 0.25 & 75 & 4 & 2.3 \\
\hline Debris Shields ${ }^{2}$ & 1.0 & $\begin{array}{l}26.6 / 6.7 \\
{[20 \mathrm{MJ} / 5 \mathrm{MJ}]}\end{array}$ & $\begin{array}{l}10 / 35 \\
{[20 \mathrm{MJ} / 5 \mathrm{MJ}]}\end{array}$ & $\begin{array}{l}2 \text { teams of } 16 \\
\text { each }\end{array}$ & 250 \\
\hline Diagnostics & 1.0 & 0.1 & 25 & 1 & 2.5 \\
\hline
\end{tabular}

a assumes each team member takes $~ 15$ minutes to change-out each of 4 shields (12 min./5 shields for a 240 -beamlet case); access to shields after $20 \mathrm{MJ}$ and $5 \mathrm{MJ}$ shots is at 48 hours

debris shields at $\geq 97 \%$ transmission is the most challenging of these tasks. A quantitative treatment of the threat to the shields requires an understanding of target emissions and materials responses.

\section{TARGET EMISSIONS}

X-Rays - Table 3 describes the $x$-ray emissions relevant to our study of system performance and first wall response. These values assume that $50 \%$ of the laser energy is converted into $x$-rays and the remainder into debris energy. Likewise, of the $20 \%$ of the fusion yield that is not neutrons, half is assumed to contribute to $\mathrm{x}$-rays and half to debris. This latter assumption is based on averaging results from many calculations but requires further experimental and theoretical confirmation. The assumed spectrum is an average between disk and Nova hohlraum spectra. The Lambertian distribution of radiation from either a laser entrance hole or the surface of a heavy-metal disk results in a range of fluences on the first wall for any given target. Since some deviation from a truly Lambertian (cosine) distribution will occur, this is conservative. The range in the debris shield column spans this distribution at the two cone angles on which the beams are located. The pulse length, expected to be nanoseconds long, is taken to be 1 ns for conservatism.

Table 3. Assumed fluences and other $X$-ray characteristics.

\begin{tabular}{|c|c|c|c|c|c|c|c|}
\hline $\begin{array}{c}\text { Shot energy } \\
\text { [Fusion } \\
\text { yield] }(\mathrm{MJ})\end{array}$ & $\begin{array}{c}\text { X-ray } \\
\text { energy } \\
\text { (MJ) }\end{array}$ & $\begin{array}{c}\text { Color } \\
\text { temperat } \\
\text { ure }(e V)\end{array}$ & $\begin{array}{c}\text { Pulse } \\
\text { duration } \\
\text { (ns) }\end{array}$ & $\begin{array}{c}\text { Fluence at } \\
\text { target } \\
\text { position } \\
{\left[20-\mathrm{cm}^{\mathrm{a}}\right]} \\
\left(\mathrm{J} / \mathrm{cm}^{2}\right)\end{array}$ & $\begin{array}{c}\text { Fluence at } \\
1 \text { st } W_{\text {all }} \text { b } \\
{[5-\mathrm{m}]} \\
\left(\mathrm{J} / \mathrm{cm}^{2}\right)\end{array}$ & $\begin{array}{c}\text { Fluence at } \\
\text { debris } \\
\text { shield } \\
{[6.75-\mathrm{m}]} \\
\left(\mathrm{J} / \mathrm{cm}^{2}\right)\end{array}$ & \#/year \\
\hline 1.0 & 0.5 & 170 & 1 & 99.5 & $0.16-.32$ & $.10-.16$ & $250-500$ \\
\hline 1.5 & 0.75 & 170 & 1 & 149 & $0.24-.48$ & $.15-.24$ & $250-500$ \\
\hline 1.8 & 0.9 & 170 & 1 & 179 & $0.29-.58$ & $.19-.29$ & $50-150$ \\
\hline $1.9[100 \mathrm{~kJ}]$ & 0.9 & 170 & 1 & 179 & $0.29-.58$ & $.19-.29$ & 100 \\
\hline $2.8[1 \mathrm{MJ}]$ & 1.0 & 200 & 1 & 199 & $0.32-.64$ & $.21-.32$ & 0 \\
\hline $6.8[5 \mathrm{MJ}]$ & 1.4 & 250 & 1 & 278.6 & $0.45-0.9$ & $.29-.45$ & 35 \\
\hline $21.8[20 \mathrm{MJ}]$ & 2.9 & 350 & 1 & 577 & $0.92-1.8$ & $.58-.92$ & 10 \\
\hline $46.8[45 \mathrm{MJ}]$ & 5.4 & 350 & 1 & 1075 & $1.7-3.5$ & $1.1-1.7$ & 0 \\
\hline
\end{tabular}

Notes: a) Target positioner at $20 \mathrm{~cm}$ from target with isotropic $x$-ray fluence.

b) First wall reflects Lambertian peak fluence to isotropic average fluence.

c) Debris shield range is for Lambertian distribution at $52^{\circ}$ and $27^{\circ}$ rings.

Debris - Table 4 describes the assumed fluences and energies of target debris. These values assume that $50 \%$ of the laser energy is converted into $x$-rays and the remainder is in debris energy. Likewise, of the $20 \%$ of the fusion yield that is not neutrons, half is assumed to contribute to $x$-rays and half to debris. A discontinuous ion temperature versus shot energy results from the increased number of ions over which to distribute the energy for a fusion target that has the additional cryogenic materials. The deposition time history influences the debris interaction with the chamber surfaces and with $x$ ray ablated materials from these surfaces. A conservative value of $30 \mu \mathrm{s}$ is assumed for all cases up to $20 \mathrm{MJ}$ based on calculations using TSUNAMI, a UC Berkeley gas dynamics code. ${ }^{2}$ Although some preliminary calculations suggest time-dependent effects (debris interaction with $x$ ray blow-off from positioner and wall) reduces the debris impach, we neglect it here for conservatism. ${ }^{3}$ The range in 
Tahle 4. Fluences and other dehris characteristics.

\begin{tabular}{|c|c|c|c|c|c|c|c|}
\hline $\begin{array}{l}\text { Shot energy } \\
\text { [Fusion } \\
\text { yield] (MJ) }\end{array}$ & $\begin{array}{c}\text { Energy in } \\
\text { debris } \\
\text { (MJ) }\end{array}$ & $\begin{array}{c}\text { Average } \\
\text { ion } \\
\text { energy } \\
(\mathrm{keV})\end{array}$ & $\begin{array}{c}\text { Pulse } \\
\text { duration } \\
(\mu s)\end{array}$ & $\begin{array}{c}\text { Fluence } \\
\text { at Tgt } \\
\text { Pos } \\
{\left[20-\mathrm{cm}^{\mathrm{a}}\right.} \\
\left(\mathrm{J} / \mathrm{cm}^{2}\right)\end{array}$ & $\begin{array}{c}\text { Fluence at } \\
\text { 1st Wallb } \\
{[5-\mathrm{m}]} \\
\left(\mathrm{J} / \mathrm{cm}^{2}\right)\end{array}$ & 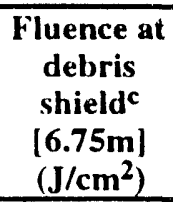 & \#/year \\
\hline 1.0 & 0.5 & 12 & 30 & 99.5 & $0.13-0.65$ & .07 & $250-500$ \\
\hline 1.5 & 0.75 & 18 & 30 & .149 & $0.19-0.95$ & .11 & $250-500$ \\
\hline 1.8 & 0.9 & 22 & 30 & 179 & $0.23-1.15$ & .13 & $50-150$ \\
\hline $1.9[100 \mathrm{~kJ}]$ & 0.901 & 2.4 & 30 & 179 & $0.24-1.2$ & .14 & 100 \\
\hline $2.8[1 \mathrm{MJ}]$ & 1.0 & 2.7 & 30 & 199 & $0.26-1.3$ & .15 & 0 \\
\hline $6.8[5 \mathrm{MJ}]$ & 1.4 & 3.8 & 30 & 278.6 & $0.59-3.0$ & .33 & 35 \\
\hline $21.8[20 \mathrm{MJ}]$ & 2.9 & 7.9 & 30 & 577 & $1.0-5.0$ & .53 & 10 \\
\hline $46.8[45 \mathrm{MJ}]$ & 5.4 & 14.7 & 20 & 1075 & $1.6-9$ & .88 & 0 \\
\hline
\end{tabular}

Notes: a) Target positioner at $20 \mathrm{~cm}$ from target with isotropic fluence.

b) First wall reflects an isotropic average fluence with $5 x$ fluence from jets.

c) Debris shield range is for an isotropic distribution .

first wall fluences addresses the "jetting" phenomena observed with Nova hohlraums.

Neutrons - Neutron fluences were determined using $3.55 \times 10^{17} 14.1-\mathrm{MeV}$ neutrons emitted per $\mathrm{MJ}$ of fusion yield. The fluences were calculated for the target positioner $(20 \mathrm{~cm})$, chamber first wall $(5 \mathrm{~m})$, and debris shield $(6.75 \mathrm{~m})$, and are shown in Table 5 . The neutron fluence is significant in that it can melt portions of the target positioner and in determining post-shot radioactivity levels. The neutron fluence at the fused silica debris shields is insignificant ${ }^{4}$ with respect to radiation damage.

Shrapnel - Shrapnel (defined as material in a liquid or solid state) will be produced from structures in the vicinity of the target which are not vaporized by the laser or yield energy. The primary sources will be the target support stalk for non-cryogenic targets and the stainless steel cooling tubes for the cryogenic type. These structures are heated and broken up by neutrons, $\mathbf{x}$-rays, and target debris. Both solid fragments and liquid droplets will be propelled radially at velocities of 300 to $3000 \mathrm{~m} / \mathrm{s}$. The anticipated size distribution for fragmentation of the stainless steel tubes ${ }^{5}$ is shown in Figure 3.

\section{RESPONSE OF CHAMBER SURFACES}

The basis for the design of target area components is that they support the assumed experimental plan and shot rate. This requirement has two implications for all component surfaces: they must continue to function with the assumed maintenance schedule and they must not compromise the performance of other systems, with optics protection being the most sensitive and important. Therefore the response of each chamber system has been designed to minimize ablated mass which can deposit on the laser optics and obscure the beams.

Table 5. Assumed neutron fluences at the target positioner, first wall, and debris shields.

\begin{tabular}{|c|c|c|c|c|c|}
\hline $\begin{array}{l}\text { Shot energy } \\
\text { [Fusion yield] } \\
\text { (MJ) }\end{array}$ & $\begin{array}{l}\text { Neutron } \\
\text { energy } \\
(\mathrm{MeV})\end{array}$ & $\begin{array}{c}\text { Fluence at } \\
\text { Tgt Pos } \\
\left(\mathbf{n} / \mathrm{cm}^{2}\right) \\
{[20 \mathrm{~cm}]} \\
\end{array}$ & $\begin{array}{c}\text { Fluence at } \\
\text { 1st Wall } \\
\left(\mathrm{n} / \mathrm{cm}^{2}\right)\end{array}$ & $\begin{array}{c}\text { Fluence at } \\
\text { Debris Shield } \\
{[6.75 \mathrm{~m}]} \\
\left(\mathrm{n} / \mathrm{cm}^{2}\right) \\
\end{array}$ & \#/year \\
\hline $1.9[100 \mathrm{~kJ}]$ & 14 & $7 \times 10^{12}$ & $1.12 \times 10^{10}$ & $6.14 \times 10^{9}$ & 100 \\
\hline $2.8[1 \mathrm{MJ}]$ & 14 & $7 \times 10^{13}$ & $1.12 \times 10^{11}$ & $6.14 \times 10^{10}$ & 0 \\
\hline $6.8[5 \mathrm{MJ}]$ & 14 & $3.5 \times 10^{14}$ & $5.6 \times 10^{11}$ & $3.1 \times 10^{11}$ & 35 \\
\hline $21.8[20 \mathrm{MJ}]$ & 14 & $1.4 \times 10^{15}$ & $2.24 \times 10^{12}$ & $1.23 \times 10^{12}$ & 10 \\
\hline $46.8[45 \mathrm{MJ}]$ & 14 & $3.5 \times 10^{15}$ & $5.6 \times 10^{12}$ & $3 \times 10^{12}$ & 0 \\
\hline
\end{tabular}

NOTE: Neutron fluences are those incident on the locations indicated and do not include scattering. 


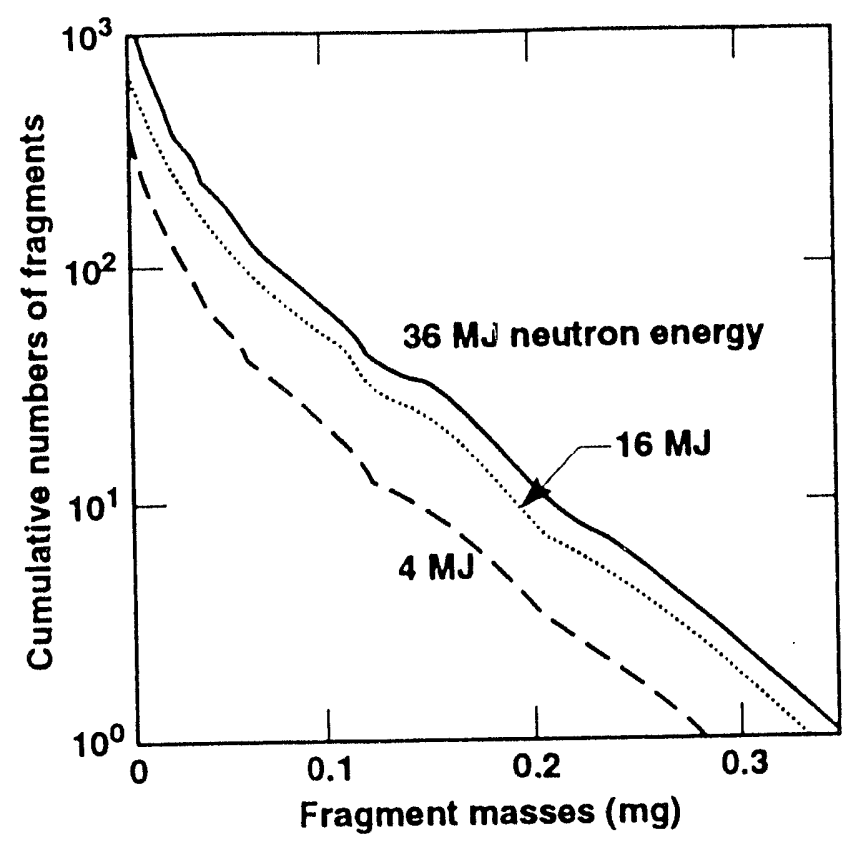

40-00-0384-1095pub

Figure 3. Anticipate size distribution for fragmentation of cryogenic stainless steel tubes for various fusion yields.

\section{FIRST SURFACE MATERIALS}

Prediciions indicate that $x$-ray fluences in NIF will be sufficiently high to ablate a large amount of material from a bare aluminum chamber wall (hundreds of kilograms per year). Therefore the walls will be protected with a cnating of low-Z, high melting point material (such as boron or alumina) to minimize $x$-ray ablation. The material could be plasma sprayed onto aluminum panels bolted to the inside of the target chamber. This design allows damaged sections to be replaced without the requirement for in situ coating.

Calculated response of the first surface materials to $x$-ray loadings indicate that no material will beremoved by any shots up to the $5 \mathrm{MJ}$ yield case, as indicated in Table 6. First wall material blowoff at $20 \mathrm{MJ}$ may possibly deposit $20 \AA$ of material on the debris shields. This result establishes the need for large yield shots to be conducted at the end of an operational week, followed by debris shield cleaning/refurbishment.

Debris that expands isotropically, is not expected to damage the wall since the deposition times are long enough to allow the coatings to conduct away sufficient heat 10 avoid vaporization and perhaps melting. Concentrated debris from the assumed plasma jet out the laser entrance holes will cause some local melting but no vaporization. This may generate a small amount of dust in the chamber which will be collected by the $\mathrm{CO}_{2}$ cleaner and will not have a significant impact on the debris shield lifetime.

Table 6. Thickness of layer deposited on debris shield due to material ablated from target chamber wall.

\begin{tabular}{|c|c|c|}
\hline Shot (MJ) & $\begin{array}{c}\text { Deposition } \\
\text { layer at debris } \\
\text { shields } \\
(\boldsymbol{A})\end{array}$ & \#/year \\
\hline 1.0 & 0 & $250-500$ \\
\hline 1.5 & 0 & $250-500$ \\
\hline 1.8 & 0 & $50-150$ \\
\hline $1.9[100 \mathrm{~kJ}]$ & 0 & 100 \\
\hline $2.8[1 \mathrm{MJ}]$ & 0 & 0 \\
\hline $6.8[5 \mathrm{MJ}]$ & 0 & 35 \\
\hline $21.8[20 \mathrm{MJ}]$ & 20 & 10 \\
\hline $46.8[45 \mathrm{MJ}]$ & 300 & 0 \\
\hline
\end{tabular}

Neutron damage to the first wall will be insignificant. Shrapnel has the possibility of damaging isolated spots on the protective panels, but should not degrade their effectiveness significantly between maintenance periods. The unconverted light will be absorbed in special beam dumps so the remainder of the first wall will be unaffected by this energy.

\section{TARGET POSITIONER}

The target positioner will be the chamber structure closest to the target. It will see the highest fluences. The target positioner for cryogenic targets, which will be used for fusion yield shots, will be protected on its front surface with a layer of frost (probably frozen nitrogen). This layer will be ablated by target emissions and be pumped out as a noncondensible gas after the shot.

Other threats to the cryogenic target positioner are the neutrons (materials producing short-lived radioactivity will be used) and the possibility of some mechanical damage from shrapnel (materials will be tough enough to survive without significant damage). The target positioner supporting non-cryogenic targets will have its front surface steeply angled away from the target to control the direction and amount of ablated material. It is predicted that this design can lead to $<10 \mathrm{mg}$ of material removed per full laser energy, no yield shot. ${ }^{6}$ If distributed isotropically this amount of material will deposit roughly $0.1 \AA$ onto the debris shield on each shot. This is the same order as the anticipated accumulation from the target mass $(0.2 \AA$ or less per shot assuming an isotropic distribution). This rate can be accommodated. These calculations are based on the assumption of a $20 \mathrm{~cm}$ standoff from target to target positioner. If this is not possible and a closer stand-off is needed, frost protection may be required for the positioner for non-cryogenic targets. 


\section{OPTICS}

The focusing lens will be protected by a fused silica debris shield placed on the target side of the lens. The debris shield will be at near-normal incidence and will be AR coated on both sides. The main threat to the debris shields is the accumulation of material on the glass from condensation of target debris and ablated target positioner mass. Estimates for the total weekly accumulation from these sources gives $2-7 \AA$ of material (mostly low $-\mathrm{Z}$ material from the target positioner) on the shields before the week's final high-yield shot. After this shot, the shields will be replaced with another set and refurbished before the next changeout the following week.

The AR coating is expected to have an $x$-ray damage threshold of at least $0.5 \mathrm{~J} / \mathrm{cm}^{2}$ to survive shots up to $5 \mathrm{MJ}$. Other target emissions will not effect debris shield performance. The $x$-ray fluence at the shield will be below the damage threshold for the fused silica for any shot up to and including the $20 \mathrm{MJ}$ case. The fragment size distribution ${ }^{5}$ for stainless steel tube shrapnel gives a range from four hundred 50- $\mu \mathrm{m}$ diameter particles to ten million 4- $\mu \mathrm{m}$ particles. The total area of these particles is $2.5 \mathrm{~cm}^{2}$, which if isotropically distributed over one hemisphere will hit a $10^{-6}$ fraction of the wall area. Assuming the fragments do not damage (on the average) an area of the shield surface greater than ten times the particle size, the damaged fraction will be just $10^{-5}$ of the total area. This low probability will allow the weekly refurbishment of the shields o identify and repair any surface-damaged shields befure the damage becomes severe. Therefore the shrapnel will not have a significant effect on the debris shields. The assumptions of isotropy and crater size as a function of velocity must be verified experimentally. Additionally, the fragment size/velocity distribution must be confirmed as a development activity.

\section{CONCLUSIONS}

A description of Target Area systems performance shows that the target area conceptual design can meet its performance criteria.

Before the shot, the target an ea provides a vacuum of $<5 \times 10^{-5}$ Torr within 2 hours. A target, cryogenic or non-cryogenic, is placed to within $1 \mathrm{~cm}$ of chamber center with a positioner that minimizes vibration of the target. The target is then aligned to $\leq 7 \mu \mathrm{m}$ by using the Target Alignment Sensor (TAS) system. The viewers in this system will also determine if the target is ready for illumination. Diagnostics are aligned to the necessary specifications by the alignment viewers. The target is shot and data is collected.

Nearly all tritium (if present) is passed through the vacuum system and into the collection system. When cleaning is required (at least weekly and perhaps more frequently) the chamber is brought up to air. An automated $\mathrm{CO}_{2}$ pellet/snow decontamination system enters the chamber through the bottom port and cleans the chamber walls, and perhaps a portion of the debris shields and beam dumps. A vacuum is re-established within two hours after cleaning.

The condition of the debris shields will be dominated by the presence of condensed material from target positioner ablation. This could be a layer of about 2 to $7 \AA$ of mostly low- $Z$ material at the end of one week, before the large yield shot is conducted, unless a frost non-cryogenic positioner is used, reducing this to $\sim 1-2 \AA$. Shrapnel may occasionally create a significant damage site, but is not expected to create serious routine damage. This effect will be better understood when calculations of shrapnel directionality and subsequent crater sizes in fused silica are performed and validated. Crazing of the fused silica by $x$-rays is not expected for a yield of $\geq 20$ MJ. The final optics design prevents contamination buildup on the focus lens side of the debris shield by eliminating the pathway around the shield. We believe ions implanted from hohlraum debris or target positioner blowoff will not penetrate the protective layer under the AR coating so that the fused silica substrate will remain undamaged.

The condition of the target chamber wall is not expected to change significantly during operations because of the frequent cleanings envisioned in the decontamination effort. Hence there will be no significant buildup of material on the surface that could alter the $x$ ray deposition characteristics. Spall and erosion from $x$ ray and debris exposure should be minimal, although the performance of the plasma-sprayed coatings over several months of shots requires investigation. Some panels of the first wall protection may need more frequent servicing than others. The panels facing the hohlraum laser entrance holes may also experience higher damage rates from the plasma debris jets leaving the hohlraum.

The condition of the laser beam dumps are not expected to change significantly over time as a consequence of the deposition of material such as hohiraum debris. This is due to the frequent $\mathrm{CO}_{2}$ cleaning and associated decontamination. The fused silica surface will be undamaged by the incident laser light because of its high lamage threshold. There should be no $x$-ray damage for any shot up to $20 \mathrm{MJ}$ yield (an AR coating that would damage is not required here). Damage expected on the absorbing glass will be small spots that receive laser fluences above their damage threshold. These spots may fracture and some material may be spalled which will be held in place by the fused silica cover as on Nova. Occasional spall damage from shrapnel is expected. These dumps will need to be occasionally replaced/refurbished.

The analysis that supports the target area design basis is a combination of careful assumptions, data, and 
calculations. Some uncertainty exists concerning certain aspects of the source terms for $x$-rays and debris, material responses to this energy flux, and the full consequences of the matcrial responses that do occur. For this reason, we have selected what we believe are conservative values in these areas. Advanced conceptual design activities will improve our understanding of these phenomena and allow a more quantitative assessment of the degree of conservatism inherent to the system. However, the results of this preliminary survey of target area operations indicate an annual shot rate of $>600$ (for the mix of shots shown in Table 1) is feasible for this set of target area systems.

\section{REFERENCES}

1. R. Warren, "Nova-Nova Upgrade Cryogenic Targets Thermal Design Approach", Engineering Note ENE 90-068, October 1990.

2. Per. F. Peterson, "NIF 1.8 MJ No Yield Response", Presentation at NIF First Wall Workshop \#4, February 10, 1994.

3. R.R. Peterson, "University of Wisconsin Capabilities to Model NIF Target Chamber Phenomena and Initial NIF Vaporization Results:, Presentation at NIF First Wall Workshop \#2, LLNL, December 14, 1993.

4. "Effects of 14-MeV Neutrons on a Fused-Silica Lens", M.S. Singh, Internal Memo, July 27, 1988.

5. "Threats from Radiation Effects in the Proposed Nova Upgrade", R.E. Tokheim, L. Seaman, and D.R. Curran, SRI Final Report, Sept. 1992.

\section{ACKLOWEDGMENTS}

This work was performed under the auspices of the U.S. Department of Energy by Lawrence Livermore National Laboratory under Contract W-7405-Eng-48. 

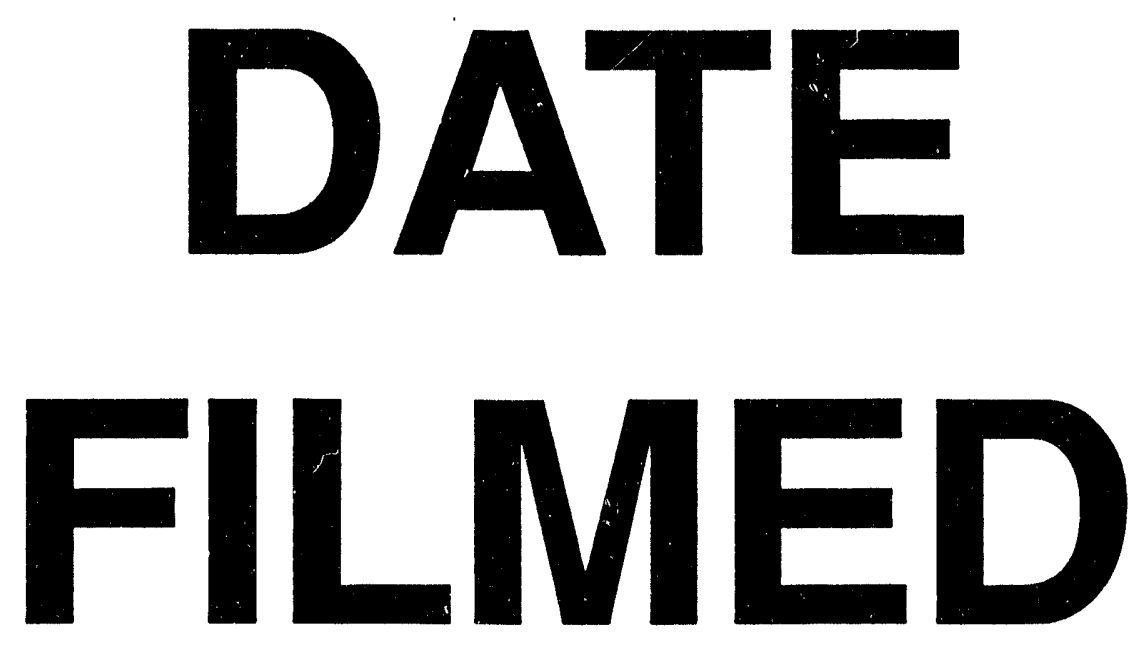

$9 / 29 / 94$
